\title{
Photoinduced chitosan-PEG hydrogels with long-term antibacterial properties
}

Received 00th January 20xx, Accepted 00th January 20xx

DOI: $10.1039 / \times 0 \times x 00000 x$

\author{
P. Sautrot-Baa , N. Razzab ${ }^{b}$ L. Breloy ${ }^{a}$, S. Abbad Andaloussic, A. Chiappone ${ }^{b}$, M. Sangermano ${ }^{b}$, C. \\ Hélary ${ }^{d}$, S. Belbeckouchea, T. Coradin ${ }^{d}$, D.-L. Versace ${ }^{a}$
}

\begin{abstract}
Photochemical processes offer the possibility to prepare functional hydrogels in green conditions that are compatible with both synthetic and natural polymers. Here hydrogels associating chitosan derivatives and poly(ethylene glycol) (PEG) have been successfully synthesized under light illumination in aqueous conditions. Kinetic studies under irradiation showed that less than 2 min were necessary to obtain fully cross-linked networks. Thermomechanical analyses and swelling experiments indicated that introduction of chitosan overall weakens the hydrogel network but can create domains of higher thermal stability than the PEG-alone structure. The resulting chitosan-PEG hydrogels demonstrated a tremendous inhibition (100\%) of the bacterial growth (Escherichia coli and Staphylococcus aureus). After 6 months ageing, one of the hydrogel preserved a high antifouling activity against Escherichia coli. This interesting result, that could be correlated with the network features, demonstrates the strong potentiality of these photochemical methods to obtain robust bio-functional materials.
\end{abstract}

\section{Introduction}

Health care-associated infections ${ }^{1-5}$ (HAIs) pose serious public and economic health problems throughout the world. This rising problem is closely related to the resistance of bacteria against antimicrobial agents and is classified as one of the highest concern by the World Health Organization. Antibiotic resistant infections dramatically reduce the effectiveness of the medicine treatments, thus notably increasing the number resistance of bacteria and their spreading over patients. Moreover, HAls are responsible for the significant increase of health care costs as new expensive therapies should be developed to treat these infections which can severely compromise the medical procedures in place such as cancer chemotherapy, organ transplantations, and could certainly prevent wound healing mechanisms.

Some studies ${ }^{4,5}$ provide estimates of the number of HAls annually observed in the US : statistics differ from one study to another, but approximately 2 million patients suffer from HAls, and nearly 90,000 are estimated to die. The British government even estimates the current death toll in worldwide to be 700,000 per year. In 2050 , the projected mortality rate linked to HAls could reach 10 million annually, which is higher than the projected rate for cancer. The overall annual costs of HAls to

a. Institut de Chimie et des Matériaux Pari-Est, UMR-CNRS 7182, UPEC, 2-8 rue Henri Dunant, 94320 Thiais, France. Corresponding author: versace@icmpe.cnrs.fr.Tel.: 01.49.78.12.28, Fax: 01.49.78.12.08

b. Politecnico di Torino, Dipartimento di Scienza Applicata e Tecnologia, C.so Duca degli Abruzzi 24, 10129 Torino, Italy.

Laboratoire Eau, Environnement, Systèmes Urbains (LEESU) - UMR-MA 102, Faculté des Sciences et Technologie, Maison des Sciences de l'Environnement, 61 avenue du Général de Gaulle, 94010 Créteil cedex, France.

d. Sorbonne Universités, UPMC Univ Paris 06, CNRS, Collège de France, UMR 7574, Laboratoire de la Chimie de la Matière Condensée de Paris, 4 place Jussieu, 75005 Paris, France.

Electronic Supplementary Information (ESI) available: Figure $S 1$ is ${ }^{1} \mathrm{H} N \mathrm{NR}$ spectrum of the commercial PEG-DA in $\mathrm{D}_{2} \mathrm{O}$; Figure $S 2$ : Raman spectra of the methacrylamidebased chitosan (chito-MA) and the native chitosan; Figure S3: optical images of the REF-PEG, chito3PEG300 and chito3PEG150 hydrogels; Figure S4: XPS spectra of the $N 1 s$ core levels of the surface of the chito3PEG150 hydrogel sample; Table S1: Structure of the polymer used and photoinitiating systems used in this study; Table S2: Polymerization rates (Rp/[MO]) of PEG-derived hydrogels and final conversions (at $t=100 \mathrm{~s}$ ) for $100 \mu \mathrm{m}$-thick films under air. [details of any supplementary information available should be included here]. See DOI: 10.1039/x0xx00000x hospitals ranged from US\$28 billion to 45 billion in 2009 and are estimated to be up to $\$ 33$ billion in 2024 .

Due to the imminent health crisis risk, numerous researches focus on the development of new strategies for limiting the antibiotic resistant infections. These problems urgently call for the synthesis of efficient and safe systems with respect to the green chemistry process. According to the global decrease of the depletable petroleum resources, scientists are turning to the use of bio-based and biodegradable monomers with intrinsic antibacterial properties. Some of the most commonly used natural polymers include antimicrobial polysaccharides and their derivatives such as chitosan ${ }^{6}$ (CS). The later is being used for the synthesis of hydrogels because of its non-toxicity, biodegradability, biocompatibility and abundance in nature. Specifically, CS provides fungistatic and bacteriostatic activities, and is therefore used intensively in wound dressings biomaterials. However, CS is limited by its reactivity and processability. In light of these consideration, many efforts to prepare functional derivatives of CS by chemical modifications have been reported ${ }^{7-13}$.

Photochemistry is widely known to be a green method and has attracted great attention because it offers many advantages over traditional techniques such as cost efficiency, mild conditions and solvent-free systems ${ }^{14}$. Contrary to thermallydriven processes which usually require elevated temperatures, photochemistry is also more likely to be compatible with biomolecules. In particular, the interest of synthesizing photopolymerizable chitosan derivatives is either to introduce chemical cross-links in the polysaccharide hydrogel or to combine it with synthetic polymers to create new hybrid materials. For instance, reacting chitosan with methyl acroloyl glycine led to photopolymerizable porous hydrogels for tissue engineering ${ }^{15}$. Photopolymerizable chitosan was also synthesized through styrenation and polymerized in the presence of camphorquinone photoinitiator upon visible light irradiation ${ }^{16}$. Glycol chitosan, a water-soluble CS derivative, has been prepared to improve the solubility of chitosan in physiological conditions and converted into a photopolymerizable polymer through methacrylation 17. Among hybrid hydrogels, photoactive CS derivatives have been 
associated under UV-light with poly(2-hydroxyethyl methacrylate) ${ }^{18}$, acrylamide ${ }^{19}$ and $\mathrm{N}$-isopropylacrylamide 20

One polymer of interest for its antifouling properties is polyethylene glycol (PEG) and its polymerizable form, polyethylene glycol diacrylate (PEG-DA), has been widely used for the hydrogels with biomedical applications 21-26. However, very few studies concern the synthesis of PEG/Chitosan hydrogels by a photochemistry process and, to the best of our knowledge, these investigations are essentially related to tissue engineering and wound dressing applications, but are not described for antibacterial purposes 27 . For example, semiinterpenetrating networks for repairing injured nerves were obtained by UV irradiation of 4-azidobenzoic acid-modified chitosan and polyethylene glycol ${ }^{28}$. Ma et al. have described the synthesis of injectable hydrogels prepared from chitosan derivative (EGAMA-CS)/polyethylene glycol dimethacrylate (PEGDA)/N, N-dimethylacrylamide (DMMA) by UV photopolymerization ${ }^{29}$. In light of these results, the same team described the synthesis of hydrogels by Michael-addition reaction and under light exposure, from new water-soluble derivative chitosan macromonomer and ethylene glycol acrylate $^{30}$. Electroconductive hydrogels were also prepared from polyaniline/chitosan/poly(ethylene glycol)diacrylate systems $^{31}$. Regarding antibacterial properties, Zou and coworkers $^{32}$ developped chitosan/PEG-based cryogels incorporating silver nanoparticles as antibacterial materials but only in the presence of silver nanoparticles.

The originality of this work is therefore to prepare antibacterial hydrogels via photochemistry process in a reduced time in aqueous conditions, by combining chitosan-based acrylate polymer and PEG-DA. For the first time, photo-rheology and Real-Time Transform Fourier Infrared spectroscopy (RTFTIR) techniques were used to clearly understand the behaviour of these systems under light activation. No investigation in literature have described in details and as we did, the photochemical behaviour of such hydrogels upon light irradiation. Furthermore, during our survey of the literature, we realized that antibacterial activities of photocrosslinkable hydrogels were studied over a few hours only while their reuse and the preservation of their antibacterial properties after several months aging were not addressed so far.

To address this point, we performed bacterial adhesion studies up to 6 months after hydrogel preparation and compared gram-positive (Staphylococcus aureus) and gramnegative (Escherichia coli) bacteria so as to identify the relative contribution of the antifouling properties of PEG and antibacterial properties of chitosan.

\section{Experimental}

Materials. Chitosan, methacrylic acid, N-(3- (dimethylamino)propyl)$\mathrm{N}^{\prime}$-ethylcarbodiimide hydrochloride (EDC), N-hydroxysuccinimmide (NHS) and 2-(N-morpholino)ethanesulfonic acid (MES) were purchased from Sigma-Aldrich. Poly(ethylene glycol) diacrylate (PEG$\mathrm{DA}, \mathrm{Mn}=596 \mathrm{~g} \cdot \mathrm{mol}^{-1}, \mathrm{SR344}$, see supporting information-Figure S1) was used as a diacrylate reactive monomer and was kindly provided by Sartomer. 1-Hydroxy-cyclohexyl-phenyl-ketone (Irgacure@ 184, I184 from BASF) was used as a type I photoinitiator. The main compounds used in this study are displayed in Table S1 (see supporting information).

\section{Methods.}

Size-exclusion chromatography (SEC). Chitosan average molecular weights and molecular weights distributions were determined by size-exclusion chromatography (SEC) coupled on-line with multiangle light scattering (MALS) and differential refractive index detectors. The detemination of the chitosan molar weight ${ }^{33}$ required its dissolution in buffer at $\mathrm{pH} 2\left(5 \mathrm{~g} \cdot \mathrm{L}^{-1}, \mathrm{dn} / \mathrm{dc}=0.187 \mathrm{~mL} \cdot \mathrm{g}^{-1}\right.$. The SEC system was composed of a LC AX pump, column ( $\mathrm{PL}$ aquagel $\mathrm{OH}$ 40+30), a DRI detector (OptilabT-Rex Wyatt) and MALS detector (Wyatt Dawn $8+$ ). The flow rate was fixed at $1 \mathrm{~mL} \cdot \mathrm{min}^{-1}$. The sample was filtered on $0.45 \mu \mathrm{m}$ unit filter before injection through a $100 \mu \mathrm{L}$ full loop. The number average $\left(M_{n}\right)$ and mass $\left(M_{w}\right)$ average molar mass of the native chitosan were found to be approximately $9.08 \mathrm{x}$ $10^{4} \mathrm{~g} \cdot \mathrm{mol}^{-1}$ and $2.09 \times 10^{5} \mathrm{~g} \cdot \mathrm{mol}^{-1}$ respectively (Polydispersity value 2.3).

Modification of Chitosan with Methacrylic Acid (Chito-MA). Chitosan $(660 \mathrm{mg})$ was dissolved in aqueous 2-(Nmorpholino)ethanesulfonic acid (MES) solution at $0.05 \mathrm{M}(250 \mathrm{~mL}$,

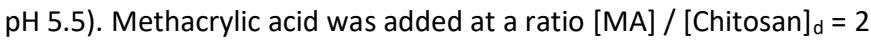
(The concentration of chitosan repeating units corresponds to [Chitosan] $]_{d}$ ). The activation of the methacrylic group was performed by addition of EDC and NHS ([EDC] / [methacrylic acid] = 1.5 and [NHS] / [EDC] = 1). After $24 \mathrm{~h}$ stirring, the formulation was dialyzed against $\mathrm{NaHCO}_{3}(0.05 \mathrm{M}, 3$ shifts), aqueous $\mathrm{HCl}(0.001 \mathrm{M}, 2$ shifts), aqueous $\mathrm{NaCl}(0.1 \mathrm{M}, 4$ shifts), and deionized water. After its conductivity has decreased below $4 \mu \mathrm{S}$ at $4{ }^{\circ} \mathrm{C}$, the formulation was freeze-dried. The degree of substitution of chitosan with methacrylic moieties was determined by ${ }^{1} \mathrm{H} N M R$ (solvent $=98 \% \mathrm{D}_{2} \mathrm{O} / 2 \% \mathrm{DCl}$, $\left.70^{\circ} \mathrm{C}\right)$. The number average $\left(\mathrm{M}_{\mathrm{n}}\right)$ and mass $(\mathrm{Mw})$ average molar mass of chito-MA were found to be approximately $1.2 \times 10^{5} \mathrm{~g} \cdot \mathrm{mol}^{-1}$ and $2.99 \times 10^{5} \mathrm{~g} \cdot \mathrm{mol}^{-1}$ respectively (Polydispersity value $\sim 2.5$ ).

NMR characterization. NMR spectra were recorded on a Bruker Avance II $400 \mathrm{MHz}$ spectrometer. ${ }^{1} \mathrm{H}$ NMR chemical shifts were referenced to the deuterated solvent signal $\left(\mathrm{D}_{2} \mathrm{O}\right) .{ }^{1} \mathrm{H}$ NMR spectra of chito-MA and native chitosan were done in a mixed $\left(98 \% \mathrm{D}_{2} \mathrm{O} / 2 \%\right.$ $\mathrm{DCl}$ ) solvent at $70^{\circ} \mathrm{C} .{ }^{1} \mathrm{H}$ NMR spectrum of the commercial PEG-DA was performed in $\mathrm{D}_{2} \mathrm{O}$.

Raman spectroscopy. Raman spectra of the unmodified chitosan and chitosan-MA were recorded using a Raman Xplora from Horiba scientific (Longjumeau, France) equipped with a laser emitting at 633 $\mathrm{nm}$. The acquisition time was fixed at $3 \mathrm{~min}$ and data treatment was performed with the LabSpec6 program (HORIBA Scientific, U.K.). No specific treatment was applied to the sample prior to analysis. 
Hydrogel synthesis. Chito-MA solutions (10 mg. $\mathrm{mL}^{-1}$ ) were prepared in an acetate buffer $(10 \mathrm{mM}, \mathrm{pH} 4)$. Mixtures containing $7 \mathrm{mg}$ of the photoinitiator (1-Hydroxy-cyclohexyl-phenyl-ketone) and $\mathrm{x} \mathrm{mg}$ of PEG-DA (150 mg or $300 \mathrm{mg}$ of PEG-DA) were prepared under magnetic stirring for 15-20 min to obtain a homogeneous solution. Then $340 \mathrm{mg}$ of the acetate solution of chito-MA were introduced into the PEG-DA/photoinitiator solutions ( $3 \mathrm{mg}$ of chito-MA are present in all the formulations). Two samples are thus formulated i.e. chito3PEG150 (3mg of chito-MA, $150 \mathrm{mg}$ of PEG-DA and $7 \mathrm{mg}$ of the photoinitiator) and chito3PEG300 (3mg of chito-MA, 300 mg of PEG$\mathrm{DA}$ and $7 \mathrm{mg}$ of the photoinitiator). Finally, $0.6 \mathrm{~mL}$ of the photoreactive solution (Chito-MA/PEG-DA/photoinitiator) was introduced into a mold and subsequently irradiated under a $\mathrm{Hg}-\mathrm{Xe}$ lamp ( $250 \mathrm{~W}, 250-700 \mathrm{~nm}$ range) for 100 seconds.

Photorheology tests. Real-time rheological measurements were performed using an Anton Paar rheometer (MCR 302) in parallel plate mode with a Hamamatsu LC8 lamp with UV bulb equipped with $8 \mathrm{~mm}$ light guide (intensity UV-A $=1.3$ and $2.7 \mathrm{~mW} / \mathrm{cm}^{2}$ ). The gap between the two plates was set to $0.2 \mathrm{~mm}$ and the sample was kept at a constant temperature $\left(25^{\circ} \mathrm{C}\right)$. Changes in elastic modulus during polymerization were measured as a function of exposure time. Oscillation tests were performed under constant shear frequency of $1 \mathrm{rad} \mathrm{s}^{-1}$ with a strain amplitude of $1 \%$ (in the linear viscoelastic region).

Thermogravimetric analysis (TGA). Thermogravimetric analysis was carried out with a Mettler TGA thermobalance. Samples obtained by dual curing with an approximate mass of $10 \mathrm{mg}$ were heated between 20 and $800{ }^{\circ} \mathrm{C}$ at a rate of $10^{\circ} \mathrm{C} \cdot \mathrm{min}^{-1}$ under air.

Dynamic Mechanical Analysis (DMA). Dynamic mechanical analyses were performed on a Triton Technology TTDMA in the tensile configuration. Samples of about $50 \mathrm{~mm}$ thickness, $2 \mathrm{~cm}$ length and $0.5 \mathrm{~cm}$ width were prepared. All the experiments were conducted with a temperature ramp of $3{ }^{\circ} \mathrm{C} / \mathrm{min}$, applying a force with a frequency of $1 \mathrm{~Hz}$ and a displacement of $20 \mathrm{~mm}$. Storage modulus $\mathrm{E}$ and tan delta were measured from $-80^{\circ} \mathrm{C}$ up to a temperature at which the rubbery state was attained. The $\mathrm{Tg}$ value was assumed as the maximum of the loss factor curve (tan delta)

X-ray photoelectron spectroscopy (XPS). XPS measurements were performed using a K-alpha Thermo Scientific photoelectron spectrometer with monochromatized $\mathrm{Al} \mathrm{K} \alpha$ excitation ( $\mathrm{hv}=$ $1486.6 \mathrm{eV})$. The elemental contents were determined by measuring integrated photo-peaks intensities after a Shirley background subtraction. The peaks areas were corrected from sensitivity factors. The X-ray spot diameter was $400 \mu \mathrm{m}$. High resolution spectrum for the N1s was obtained with a pass energy of $50 \mathrm{eV}$ with a $0.05 \mathrm{eV}$ energy step. The dwell time was $100 \mathrm{~ms}$ for the acquired spectrum. The analysis chamber base pressure was by $8.010^{-10}$ torr.
Network parameters. $M_{c}$, which corresponds to the molar mass between two adjacent crosslinks, can be calculated using FloryHuggins theory ${ }^{34}$ (eq.1).

$M_{c}=\left(-d_{p} V s \emptyset^{1 / 3}\right) /\left(\ln (1-\varnothing)+\varnothing+\chi \varnothing^{2}\right)$

where $d_{p}$ is the polymer density $V_{s}$ is the molar volume of water $\left(18 \mathrm{~cm}^{3} \cdot \mathrm{mol}^{-1}\right), \varnothing$ is the volume fraction of the polymer in the hydrogel, $\chi$ is the Flory-Huggins polymer-solvent interaction parameter.

The volume fraction of the polymer ${ }^{35}, \varnothing$, in the swollen state, can be described as eq. 2 :

$\varnothing=\left(1+\left(d_{p} / d_{s}\right)^{*}\left(m_{0} / m_{f}\right)-d_{p /} d_{s}\right)$

where $m_{0}$ and $m_{f}$ are the mass of the polymer before and after swelling, respectively, and ds is the density of the solvent.

The density of the polymeric films ${ }^{36}\left(d_{p}\right)$ was calculated using eq. 3:

$d_{p}=w / S X$

where $X$ is the average thickness of the film, $S$ is the crosssectional area and $w$ the weight of the following film.

The polymer-water interaction parameter ${ }^{37}(\chi)$ of the hydrogels was estimated via eq. 4 :

$X=1 / 2+\varnothing / 3$

Water swelling behaviour. The swelling characteristics of PEGbased hydrogels were estimated by immersing dried samples in $10 \mathrm{~mL}$ distilled water for few hours. Every $20 \mathrm{~min}$ the samples were removed from the swelling medium and blotted with a piece of paper to remove excess water on the substrate and weighted. The swelling ratio $\left(100^{*} \mathrm{~m}_{\mathrm{t}} / \mathrm{m}_{0}\right)$, where $\mathrm{m}_{0}$ and $\mathrm{m}_{\mathrm{t}}$ correspond to the weight of the dried and swollen samples, were determined and the water content at equilibrium was calculated from eq. 5 :

$Q_{H 2 O}=\left(m_{t}-m_{0}\right) / m_{t}$

Real-time InfraRed Fourier Transform Spectroscopy. Kinetics of photopolymerization were followed by Real Time Fourier transform infrared spectroscopy (RT-FTIR) using a JASCO series 4000 instrument. The liquid samples were applied to a BaF2 chip by means of calibrated wire-wound applicator. The thickness of the UV-curable film was evaluated at $100 \mu \mathrm{m}$. The RT-FTIR analyses were carried out under air conditions. Samples were irradiated at room temperature by means of a Lightningcure LC8-02 lamp from Hamamatsu, equipped with a Hg-xenon lamp (250 W, 250-700 nm range) coupled with a flexible light guide. The end of the guide was placed at a distance of $6 \mathrm{~cm}$. The maximum UV light intensity at the sample position was evaluated to be $60 \mathrm{~mW} \cdot \mathrm{cm}^{-2}$. The 
photopolymerization was monitored by the disappearance of the $-\mathrm{C}=\mathrm{C}$ - stretch peak at $1637 \mathrm{~cm}^{-1}$. Conversion rate was calculated following eq.6:

Double bonds conversion $(\%)=\left(A_{0}-A_{t}\right) / A_{0}$

where $A_{0}$ represents the initial peak area and $A_{t}$ represents its area at time $t$.

The $R_{p}$ quantities refer to the maximum rates of the polymerization reaction and were calculated from the maximum of the first derivative of the conversion versus time curves.

2.14. Antibacterial properties of the gel samples. Antibacterial assays were performed using two strains of bacteria, namely Escherichia coli ATCC25922 and Staphylococcus aureus ATCC6538. A well-known procedure based on the counting of the colony forming units (CFUs) was used to estimate the adhesion of bacteria on the gel surfaces after $2 \mathrm{~h}$ and $6 \mathrm{~h}$ of incubation 38, 39. Bacterial strains were preliminary grown aerobically overnight in Luria-Bertani broth at $37^{\circ} \mathrm{C}$ under stirring. Recovered cultures were diluted to an optical density at $600 \mathrm{~nm}$ of 0.05 ( $c$ a $10^{7}$ bacteria per $\mathrm{mL}$ ) in sterile LB broth. At this point, antibacterial and rectangular materials $(1.5 \mathrm{~cm} \times 3 \mathrm{~cm} \times 0.5 \mathrm{~cm})$ were immersed in the culture. The corresponding vials were placed on a slantwise rotating wheel to avoid sedimentation of bacteria and incubated for $2 \mathrm{~h}$ and 6h (INFORS AG-CH 4103, Bottmingen-Basel, Switzerland). After this delay, samples were rinsed seven times with sterile saline solution $(\mathrm{NaCl}, 0.9 \% \mathrm{w} / \mathrm{v})$ to remove any non-adherent cells and transferred to $2 \mathrm{~mL}$ sterile saline (solution A). After vigorous vortexing for $30 \mathrm{~s}$, samples were placed in $2 \mathrm{~mL}$ sterile saline (solution B) and sonicated in a Branson 2200 sonicator for $3 \mathrm{~min}$. Finally they were transferred to $2 \mathrm{~mL}$ sterile saline (solution $C$ ) and vigorously vortexed for $30 \mathrm{~s}$. Suspensions A, B and C were pooled, serially diluted and bacterial population determined by the Plate Count technique as Colony Forming Units (CFU) per mL. Each experiment was done in four replicates. Live/dead assays on E. coli and $S$. aureus have been done according to our previous investigation 40 . To evaluate the stability of the hydrogels, samples were kept for 6 months in the fridge $\left(+2^{\circ} \mathrm{C}\right)$. The conditions for bacterial culture and colonization assays were the same as described above except that only $6 \mathrm{~h}$ incubation was performed. Round samples with a diameter of $1.5 \mathrm{~cm}$ were used for the antibacterial tests. At the end of incubation, the hydrogel supernatant was recovered. After rinsing in sterile saline solutions to get rid-off loosely-adhered cells, the hydrogel surface was carefully scratched in sterile saline solutions to insure optimal bacteria recovery. A control bacteria suspension was also incubated in the absence of hydrogels. The bacteria content of these three sets of samples was measured by the Plate Count technique and provided as per $\mathrm{mL}$. Each experiment was done four times.

\section{Results}

Chitosan modification. A few methods such as using acetyl chloride ${ }^{41,42}$ with pyridine, acetic anhydride with pyridine and 4-(dimethylamino)pyridine ${ }^{43}$, carboxylic acids activated in situ with tosyl chloride 44, 45, iminium chloride 46 and 1,1'carbonyldiimidazole 46, 47 and acetic anhydride activated with strong acids or metal catalysts are reported in the literature for the esterification of polysaccharides. In our case, a simple and green esterification process was needed to graft methacrylate functional group. To this end, [1-ethyl-3(dimethylamino)propyl]carbo-diimide hydrochloride (EDC) coupling with $\mathrm{N}$-hydroxysuccinimide 48 (NHS) was selected because of its efficiency to anchor methacrylate moieties on chitosan backbone via the addition of the pendant amine groups of the chitosan to the activated carboxylic acid group of methacrylic acid.

Chemical structures of native chitosan and modified chitoMA were studied by ${ }^{1} \mathrm{H}$ NMR and Raman spectroscopies. The success of the functionalization was first demonstrated by $1 \mathrm{H}$ NMR (Figure 1). When the two spectra are compared, new signals appear at 5.6 and $6 \mathrm{ppm}$ for Chito-MA that are attributed to the vinyl protons of the methacrylamide moieties. The methyl group of the methacrylamide moiety was evidenced at ca. $1.9 \mathrm{ppm}$ on chito-MA (Figure $1 \mathrm{~A}, \mathrm{Hd}$ ). Finally, the anomeric protons of chitosan and chito-MA were observed from 4.5 to 5 $\mathrm{ppm}(\mathrm{Ha}, \mathrm{Hc}$ and $\mathrm{Hg}$ ). The degree of acetylation of the native chitosan was evaluated at $20 \%$ and the degree of substitution of this chitosan was estimated at $27 \%$ by comparing the areas of the signals attributed to the vinyl protons of the inserted methacrylate moiety with that ones arising from the anomeric protons. This result is in accordance with literature data 49 following the same experimental conditions of chitosan modification.

Raman spectra (Figure S2) of both the pristine chitosan and chito-MA also evidence the successful grafting of the methacrylate function. Figure S2A and Figure S2B display the Raman spectra of chito-MA and native chitosan, respectively. For native chitosan, two peaks are found at 3370 and $3306 \mathrm{~cm}$ ${ }^{1}$ that could be assigned respectively to the stretching vibrations of $-\mathrm{OH}$ and $-\mathrm{NH}_{2}$ groups ${ }^{50}$. Two intense peaks between 2950 and $2850 \mathrm{~cm}-1$ correspond to $\mathrm{v}\left(\mathrm{CH}_{3}\right)$ and $\mathrm{v}\left(\mathrm{CH}_{2}\right)$ vibrations, respectively. A small shoulder at $1591 \mathrm{~cm}^{-1}$ signs for the in-plane bending vibrations of $\mathrm{NH} 2$ groups. The bands in the range 900$1500 \mathrm{~cm}^{-1}$ can be assigned to: $\delta\left(\mathrm{CH}_{2}\right)$ and $\delta(\mathrm{CH})$ at $1377 \mathrm{~cm}^{-1}$; $\delta(\mathrm{OH} . . . \mathrm{H})$ and $\mathrm{v}(\mathrm{C}-\mathrm{O})$ at $1263 \mathrm{~cm}^{-1} ; \mathrm{v}(\mathrm{C}-\mathrm{O}-\mathrm{C}), \mathrm{v}(\mathrm{C}-\mathrm{OH})$ and $\mathrm{v}(\mathrm{C}-$ $\mathrm{CH}_{2}$ ) at 1146, 1114 and $1093 \mathrm{~cm}^{-1}$. For chito-MA (Figure S2A), modification of the spectra are observed in the $3400-3300 \mathrm{~cm}^{-1}$ region, indicating a perturbation of the hydrogen bond network after grafting. The $\mathrm{v}\left(\mathrm{CH}_{3}\right)$ peaks at ca. $2900 \mathrm{~cm}^{-1}$ are also modified, in agreement with the introduction of the methylacrylamide function. A broad band between 1600 and $1650 \mathrm{~cm}^{-1}$ is also apparent corresponding to the $-C=C$ - stretching vibration of the methacrylamide function 51,52 and to the $\mathrm{C}=\mathrm{O}$ 
stretching vibration of amide I ${ }^{51,52}$. Finally, a new peak appears at ca. $1416 \mathrm{~cm}^{-1}$ due to the $\mathrm{C}=\mathrm{C}$ scissors deformation of the methacrylamide function.

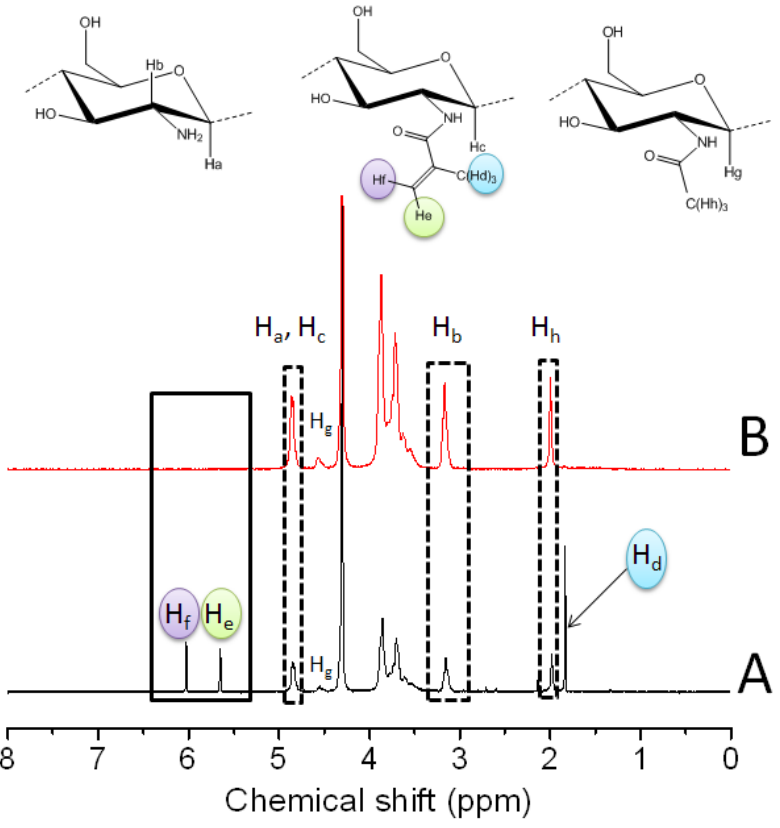

Figure 1. ${ }^{1} \mathrm{H}$ NMR spectra of A) methacrylamide-based chitosan (Chito-MA) and $B$ ) native chitosan. Solvent $=98 \% \mathrm{D}_{2} \mathrm{O} / 2 \% \mathrm{DCl}$ Temperature $=70^{\circ} \mathrm{C}$.

Photopolymerization kinetics. PEG-derived hydrogels were synthesized by photopolymerization upon UV-light exposure using 1-Hydroxy-cyclohexyl-phenyl-ketone as a photoinitiator. Photoreactivity of the synthesized hydrogels (REF-PEG, chito3PEG150 and chito3PEG300) was investigated by photorheology tests and RT-FTIR. Swelling and water uptake were determined for all samples along with the determination of the molecular weight between crosslinks ${ }^{53}$. To follow the photopolymerization kinetics, the variation of $\mathrm{G}^{\prime}$ elastic modulus during UV-light irradiation under constant oscillation frequency was monitored (Figure 2). Figure 2A shows the kinetics of the reaction when the intensity of the curing irradiation was set to $1.3 \mathrm{~mW} / \mathrm{cm}^{2}$. While no variation in $\mathrm{G}^{\prime}$ is observed for the mixture before irradiation, exposure to UV light triggered, after a delay that varied with the considered sample, a fast reaction and the plateau in $\mathrm{G}^{\prime}$ value was reached after a maximum of $40 \mathrm{~s}$. For neat PEG-DA (REF-PEG), the delay before $\mathrm{G}^{\prime}$ increase was ca. $5 \mathrm{~S}$ and the plateau was reached almost instantaneously. Chito3PEG300 showed a similar delay but the increase in $G^{\prime}$ was more progressive and the final modulus was higher compared to REF-PEG. The behavior of chito3PEG150 was similar to chito3PEG300 except for a longer delay (ca. $8 \mathrm{~s}$ ) before $\mathrm{G}^{\prime}$ increased. Thus it appears that the delay required to start the reaction is related to PEG-DA amount (which is similar for REF-REG and chito3PEG300 but two times smaller than chito3PEG150) while the following progress of the reaction and final $G^{\prime}$ value is influenced by the presence of chitosan. In order to speed up the reaction, a higher light intensity can be set. As shown in Figure 2B, using an irradiation power of $2.7 \mathrm{~mW} . \mathrm{cm}^{-2}$ allows to suppress the delay between irradiation and $G^{\prime}$ increase for all samples. Moreover, this increase is sharp in all conditions with a first maximum being reached within less than $5 \mathrm{~s}$. Noticeably, $\mathrm{G}^{\prime}$ then continues to increase for REF-REG and chito3PEG300 to reach a similar value of ca. $5 \cdot 10^{5} \mathrm{~Pa}$.
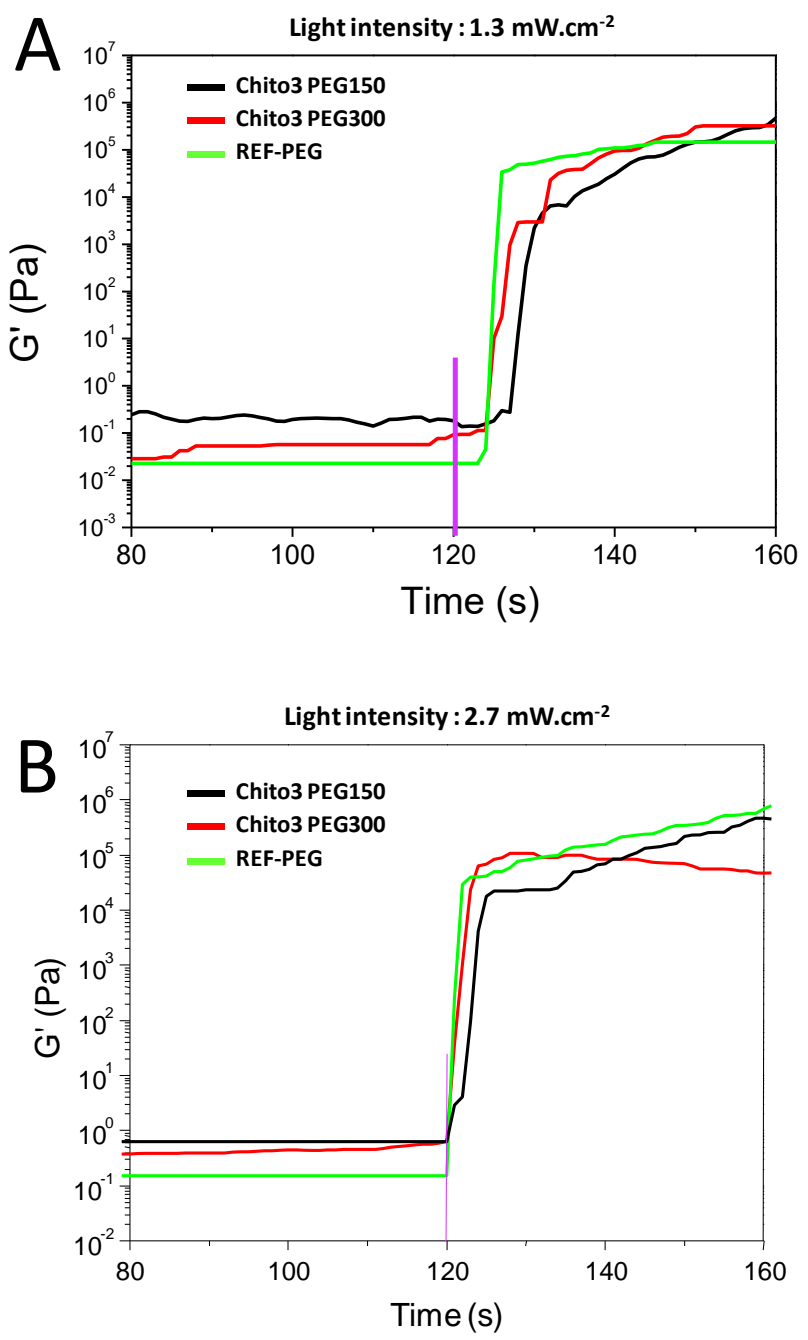

Figure 2. Photo-rheology characterization of REF-PEG (only PEGDA), chito3PEG150 and chito3PEG300 formulations using the irradiation intensities of A) $1.3 \mathrm{~mW} / \mathrm{cm}^{2}$ and B) $2.7 \mathrm{~mW} / \mathrm{cm}^{2}$. Purple verical bar indicates the start of irradiation.

To complement photo-rheology tests, RT-FTIR experiments were performed on a BaF2 chip, fixing the thickness of the photopolymerized films to $100 \mu \mathrm{m}$. Under light irradiation, the photolysis of the hydroxyketone initiator occurs by a fragmentation reaction process (Norrish I), and two radical species are thus produced, i.e. benzoyl and hydroxy-cyclohexyl radicals ${ }^{53,54}$ (Scheme 1 ). These later species are able to add up 
on the carbon double bonds of chito-MA and PEG-DA, thus allowing the initiation of the photopolymerization. This reaction leads to crosslink structures, yielding a three-dimensional insoluble polymer networks. Therefore the decrease of the terminal $-\mathrm{C}=\mathrm{C}-$ stretching vibration at $1637 \mathrm{~cm}^{-1}$ was monitored by RT-FTIR upon UV-light exposure $\left(60 \mathrm{~mW} \cdot \mathrm{cm}^{-2}\right)$. Typical RTFTIR curves for the photopolymerization of PEG-derived hydrogels are displayed in Figure 3. Rates of polymerization $\mathrm{Rp} /\left[\mathrm{M}_{0}\right]$ and final conversions are summarized in Table S2 (see supporting information). In all cases, high conversions (> 90\%) are obtained under air, suggesting that no oxygen inhibition occurs during the photopolymerization process. Hence, more than $90 \%$ of the $-\mathrm{C}=\mathrm{C}-$ functions have been consumed after 50 $s$ of irradiation for REF-PEG and the double bond conversion even reaches $100 \%$ with chito3PEG150 and chito3PEG300 after $75 \mathrm{~s}$ and $25 \mathrm{~s}$, respectively. Interestingly, the polymerization rate is the highest when only PEG-DA is present (REF-PEG). Keeping PEG-DA concentration constant, the introduction of chito-MA (chito3PEG300) decreases this rate by a factor of ca. 3 while decreasing PEG-DA concentration (chito3PEG150) at constant chito-MA content further decreases it by the same factor. Therefore, in agreement with photorheology experiments, the presence of chitosan slows down the reaction but seems to increase its efficiency while the decrease of PEGDA in presence of chitosan also decrease the polymerization rate without impacting on the final conversion.

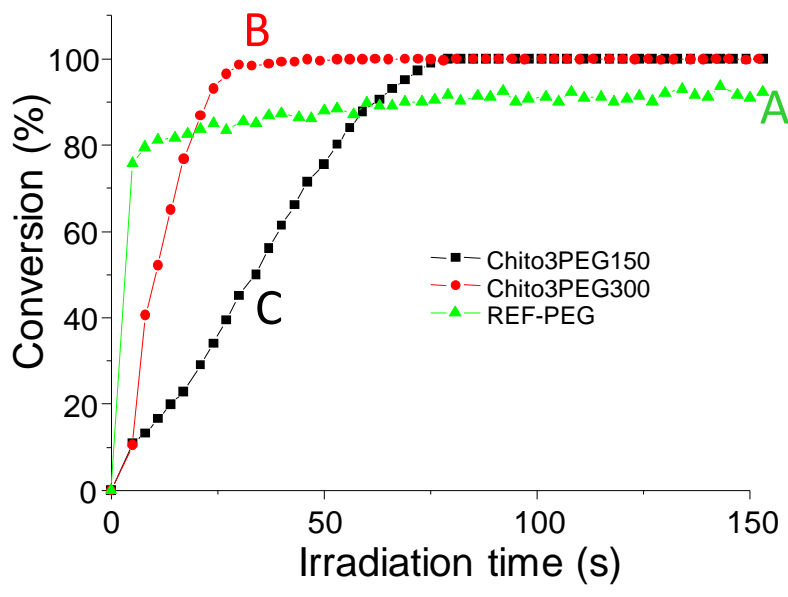

Figure 3. Photopolymerization kinetics of the formulations containing PEG-DA and Chito-MA: A) REF-PEG, B) Chito3PEG300 and C) Chito3PEG150. Irradiation under air. Hg-Xe lamp. Intensity $=60 \mathrm{~mW} / \mathrm{cm}^{2}$.

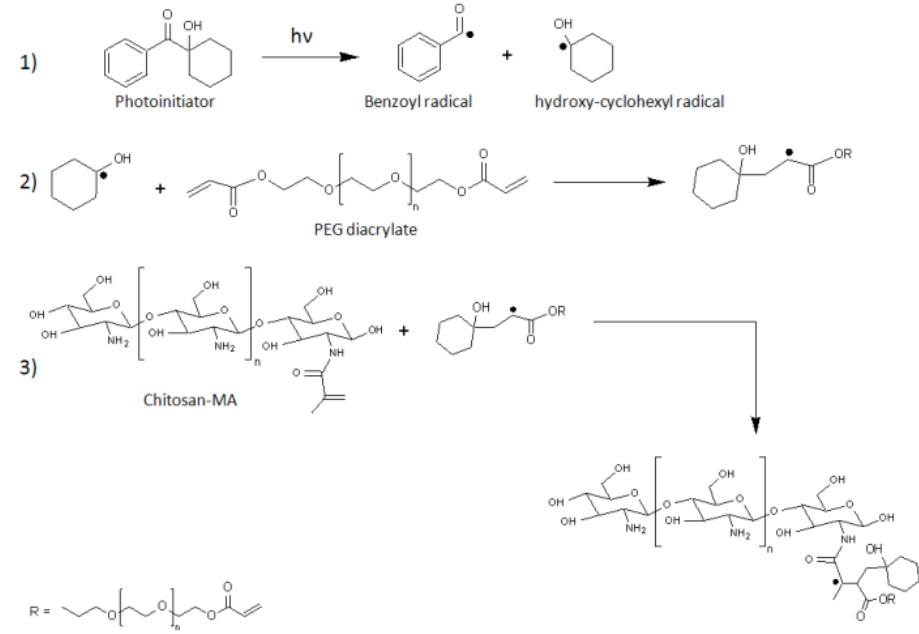

Scheme 1. Schematic representation of the free-radical photoinduced cross-linking between PEG-DA and Chito-MA.

Thermal properties of the hydrogels. A series of bulk hydrogels (REF-PEG, chito3PEG150 and chito3PEG300) were then prepared. Optical images evidenced that REF-PEG is welltransparent whereas introduction of chito-MA leads to opaque materials (Figure S3, see supporting information). Thermogravimetric analyses of the three hydrogels are shown in Figure 4. The reference polymer matrix (REF-PEG without chito-MA), showed a slight weight loss of about $2 \%$ between room temperature and $150{ }^{\circ} \mathrm{C}$ that could be associated to the departure of a small amount of water embedded in the polymer network. In the same temperature range, the samples containing chito-MA showed larger weight losses that were proportional to the amount of water coming from the chito-MA solution. At higher temperatures, the first derivate of the weight loss over time allowed us to have clearer look at the thermal degradation. The REF-PEG sample showed a two-step degradation with a major event centered at $410{ }^{\circ} \mathrm{C}$, associated with almost the total weight loss of the matrix (only $6 \%$ of the total weight remains after this degradation stage) and a much weaker peak at $550^{\circ} \mathrm{C}$. When chito-MA was present, a threestep decomposition process was observed. For chito3PEG300, the step at $410{ }^{\circ} \mathrm{C}$ is still observed but a new thermal event is evidenced at $355^{\circ} \mathrm{C}$ while the final peak has apparently shifted to much lower temperature $\left(492^{\circ} \mathrm{C}\right.$ instead of $550^{\circ} \mathrm{C}$ for REFPEG). For chito3PEG150, three events are also observed but the peaks broadness makes the precise determination of the corresponding temperature more difficult suggests that the material has a significant degree of heterogeneity. The first decomposition occurring between $300-360^{\circ} \mathrm{C}$, that was not observed on the case of neat polymer matrix, is typical of chitosan due to further dehydratation, deacetylation and chitosan depolymerization ${ }^{55}$. The other two thermal events are present in REF-PEG thermograms and can therefore be attributed to the PEG matrix decomposition. The event near $400-410^{\circ} \mathrm{C}$ is not modified in chito3PEG300 but is shifted in 
chito3PEG150, suggesting that it mainly depends on the PEG network whereas the final peak is shifted to lower temperature when chito-MA is present, indicating that it depends on PEGchitosan interactions that appear detrimental to the matrix stability.
A

C

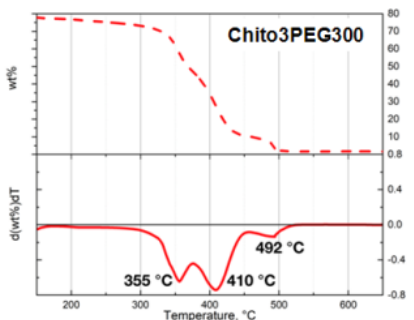

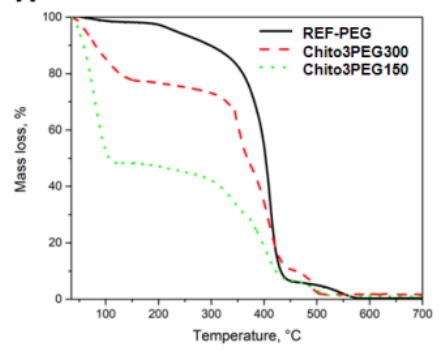

B

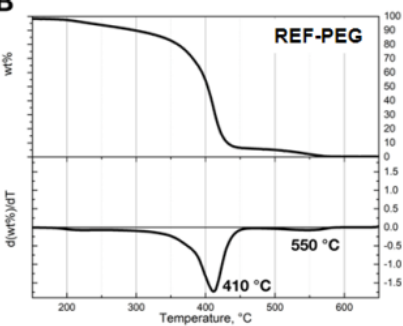

D

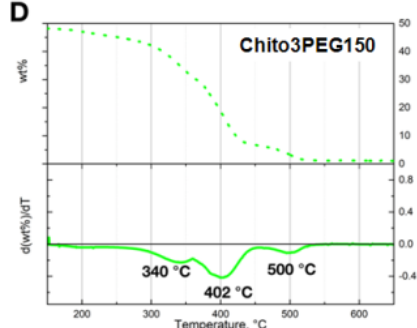

Figure 4. Thermal decomposition of poly(ethylene glycol) polymer matrices with or without chitosan-MA. (A) Thermogravimetric profiles between 35 to $700{ }^{\circ} \mathrm{C}$ for pristine polymer matrix (black full line), chito3PEG300 (red dashed line) and chito3PEG150 (green dotted line). Derivative thermogravimetric analyses of REF-PEG (B), chito3PEG300 (C) and chito3PEG150 (D)

Viscoelastic properties of the crosslinked films with and without chito-MA were examined by DMA. The results in terms of tan delta and storage modulus are reported in Figure 5. The glass transition temperatures $(\mathrm{Tg})$ were taken from the maximum of the $\tan (\delta)$. In agreement with our previous investigations ${ }^{56}$, REF-PEG led a relatively sharp peak, allowing for a suitable determination of $\mathrm{Tg}$ at $-21^{\circ} \mathrm{C}$. The addition of chito-MA at constant PEG content caused a shift of the $\tan (\delta)$ maxima towards lower temperatures and a broadening of the peak. We identified a $\mathrm{Tg}$ at ca. $-42^{\circ} \mathrm{C}$ for the chito3PEG300. For chito3PEG150, a broad peak of low relative intensity was evidenced in the same temperature region (ca. $-44^{\circ} \mathrm{C}$ ). Moreover, another one near $-20^{\circ} \mathrm{C}$ and a third one at ca. $+2{ }^{\circ} \mathrm{C}$ are present on the $\tan (\delta)$ curve, suggesting that a phaseseparation-like process has occurred during the formation of chito3PEG150 57. Evolution of the storage modulus with temperature showed that REF-PEG behave as a homogeneous material, with a marked decrease of the modulus near the $\mathrm{Tg}$. It also confirmed the presence of at least two different networks in chito3PEG150. However, two steps and therefore at least two networks were also evidenced for chito3PEG300, suggesting that the broad peak observed in the $\tan (\delta)$ curve is in fact the merging of at least two peaks with close maxima, thus corresponding to two domains with close structures. The storage modulus in the rubbery state (above the $\mathrm{Tg}$ ) was $29 \mathrm{MPa}$ for REF-PEG, 6.4 MPa for chito3PEG300 and of 1.4 MPa for chito3PEG150. These values are in agreement with the TGA data suggesting that the introduction of chito-MA or decrease of PEG content are detrimental to the stability of the network.
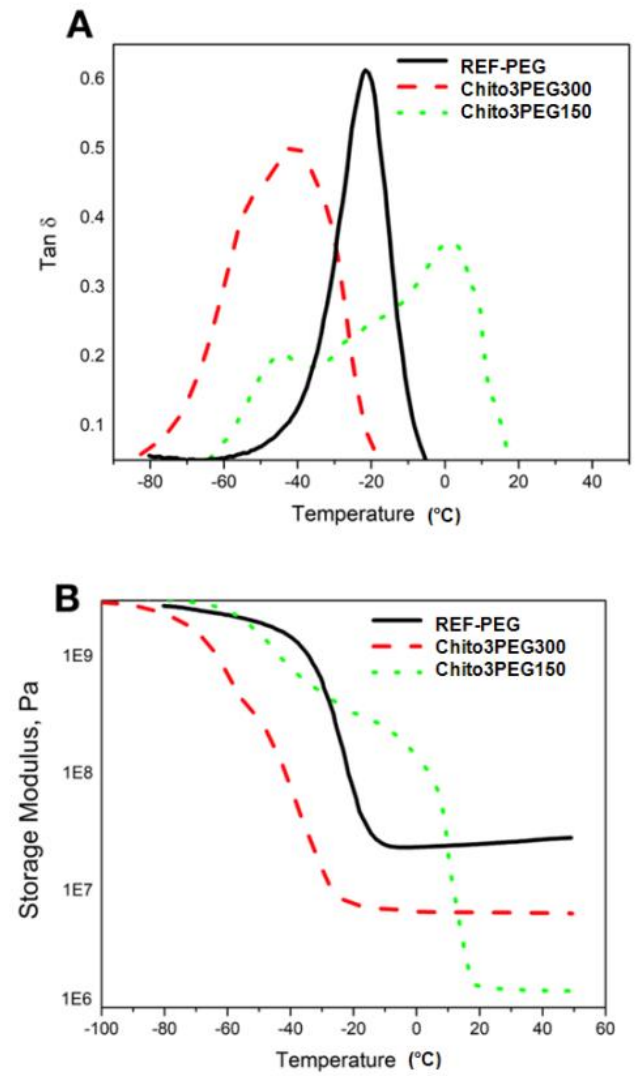

Figure 5. Tan delta (A) and storage modulus (B) from DMA. Pristine polymer matrix (black full line), chito3PEG300 (red dashed line) and chito3PEG150 (green dotted line).

Swelling characteristics of the hydrogels. The three types of hydrogels were dried and used for swelling experiments (Figure 6). From these data, it was possible to calculate the gel volume fraction $(\varnothing)$, the molecular weight between two adjacent crosslinks $\left(M_{c}\right)$ and the water content at equilibrium $\left(Q_{\mathrm{H} 2 \mathrm{O}}\right)$ (Table 1$)$. As shown on Figure 7, REF-PEG has the swelling ratio at equilibrium (ca. $45 \%$ ), that is reached after $6 \mathrm{~h}$. Introduction of chito-MA decreases the time necessary to reach equilibrium to ca. $2 \mathrm{~h}$ and the maximum swelling ratio is ca. $125 \%$. However, if less PEG is present, it further increases to ca. $280 \%$. The polymer fraction in the gel $\varnothing$ also decreases along the same trend, from 0.98 for REF-PEG to 0.45 for chito3PEG150. Calculation of $\mathrm{Mc}$ indicates a high increase in this parameter between REF-PEG and chito3PEG300 and a more moderate one between chito3PEG300 and chitoPEG150, suggesting that PEGDA concentration has a predominent influence on $M_{c}$. Finally, $\mathrm{Q}_{\mathrm{H} 2 \mathrm{O}}$ decreased when chito-MA was added while decreasing PEG content increases this value. 
Altogether, introduction of chito-MA decreases the crosslinking density, in agreement with the observed decrease in storage modulus, and therefore increase swelling capacity. However it induces a decrease in $\mathrm{Q}_{\mathrm{H} 2 \mathrm{O}}$, i.e. the weight percent of water in the gel, which may reflect the lower hydrophilic character of the chitosan chain compared to PEG. As expected, when PEG content decreases, the cross-link density is lower and therefore the swelling capacity is higher. However $Q_{H 2 O}$ is slightly larger which is in agreement with the lower total polymer content in chito3PEG150 compared to chito3PEG300.

Table 1. Physico-chemical properties of the photosynthesized chitosan-PEG hydrogels

\begin{tabular}{ccccc}
\hline Samples & $\begin{array}{c}\text { Swelling } \\
\text { ratio (\%) }\end{array}$ & $\begin{array}{c}\text { Gel } \\
\text { fraction } \varnothing\end{array}$ & $\begin{array}{c}M_{c}{ }^{\mathrm{a}} \\
\left(\mathrm{g} \cdot \mathrm{mol}^{-1}\right)\end{array}$ & $\begin{array}{c}Q_{\mathrm{H} 20^{\mathrm{b}}} \\
(\%)\end{array}$ \\
\hline REF-PEG & $45 \pm 6$ & $0.98 \pm 0.01$ & $156 \pm 53$ & $\begin{array}{c}36.3 \pm \\
2.6\end{array}$ \\
& & & & \\
Chito3PEG300 & $125 \pm 1$ & $0.71 \pm 0.01$ & $3392 \pm$ & $16.9 \pm$ \\
& & & 543 & 0.7 \\
Chito3PEG150 & $279 \pm 12$ & $0.43 \pm 0.02$ & $4711 \pm$ & $25.2 \pm$ \\
& & & 309 & 1.5 \\
\hline
\end{tabular}

a: Molecular weight between crosslinks

b: Water Content at equilibrium

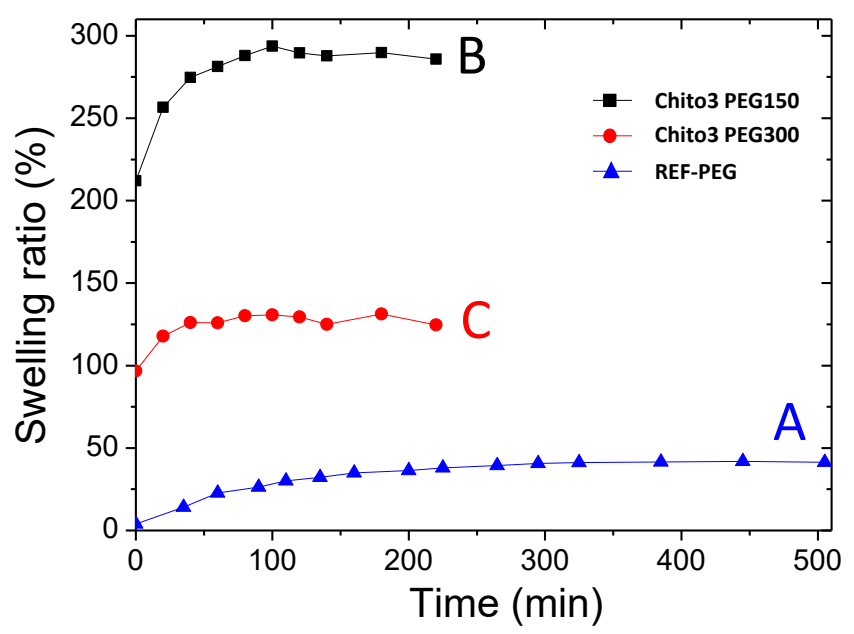

Figure 6. Swelling ratio as a function of time for A) REF-PEG, B) chito3PEG150 and C) chito3PEG300.

Anti-adhesion and bactericidal properties against $E$. coli and $S$. aureus. To evaluate the ability of hydrogels to prevent bacterial adhesion, they were incubated in the presence of $E$. coli and $S$. aureus suspensions for 2 and 6 hours. After these delays, bacteria were detached from the surface under sonication and the bacterial surface density was determined as the number of colony forming units (CFUs) per $\mathrm{cm}^{2}$ by the Plate counting technique. As shown in Figure 7, E. coli and S. aureus bacteria could only be found on the surface of the REF-PEG hydrogels. Yet the CFUs density on the REF-PEG hydrogels was low $\left(<10^{5}\right.$ cells $\left./ \mathrm{cm}^{2}\right)$ compared to the initial cell population $\left(\mathrm{OD}_{600}=0.05\right.$ corresponds to ca. $10^{7}$ bacteria per $\mathrm{mL}$ ) but it slightly increased from 2 to $6 \mathrm{~h}$ for $E$. coli. Such low density on REF-PEG samples can be attributed to the previously-reported antifouling (but not biocidal) properties of the poly(ethylene glycol) ${ }^{56}$. On the contrary, the presence of chitosan in chito3PEG150 and chito3PEG300 hydrogels led to the absence of any detectable living bacteria at the surface of both hydrogels after $2 \mathrm{~h}$ and 6 $h$. The same trend is observed in the presence of $S$. aureus.
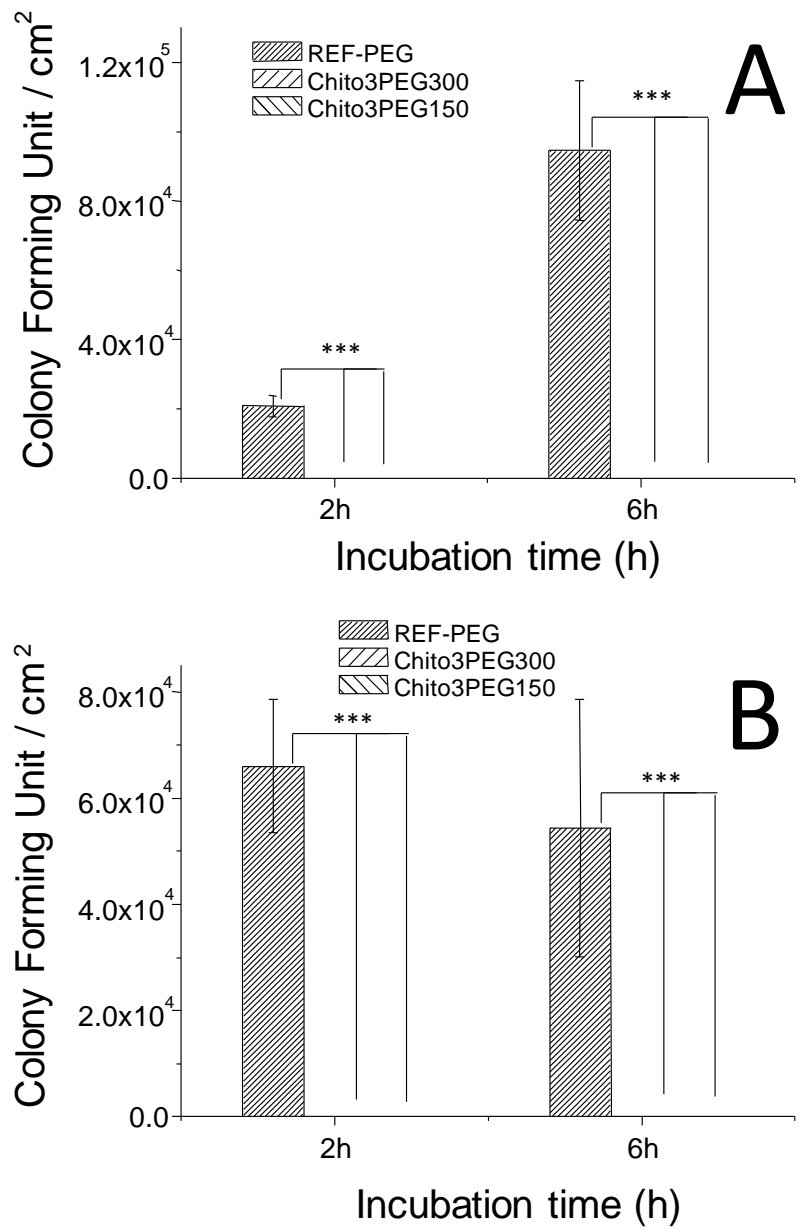

Figure 7. Comparison of the anti-bacterial adhesion properties of REF-PEG, chito3PEG300 and chito3PEG150 hydrogels after 2 $\mathrm{h}$ and $6 \mathrm{~h}$ incubation with (A) E. coli and (B) S. aureus as determine by living bacteria density on the hydrogel surface $(* * *$ is statistically different with $p<0.001)$. 


\section{E. coli}
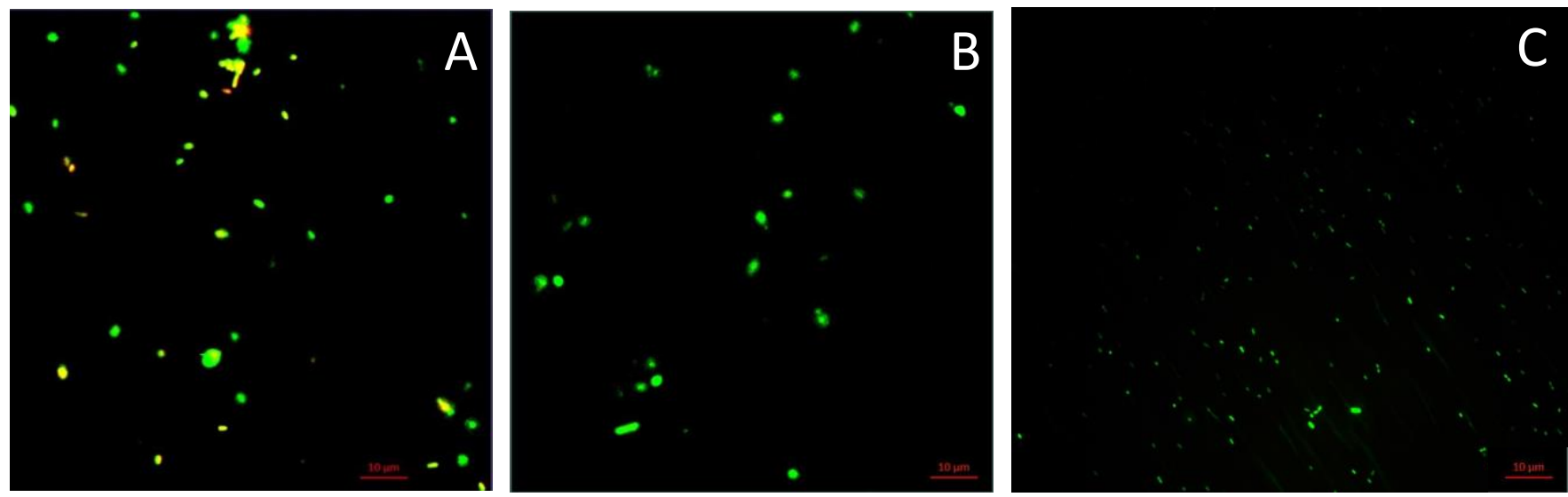

S. aureus

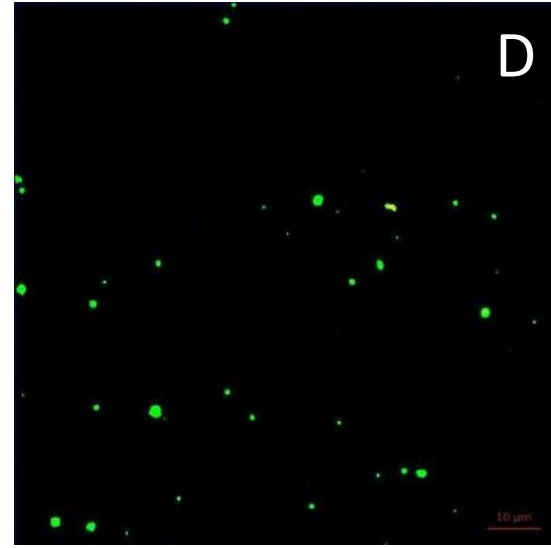

Chito3PEG150

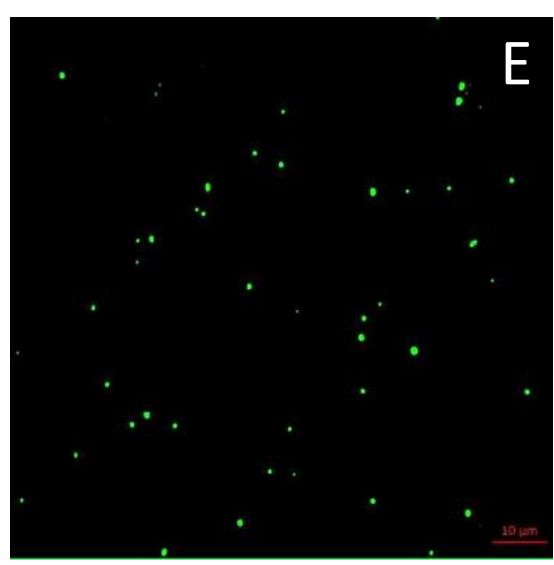

Chito3PEG300

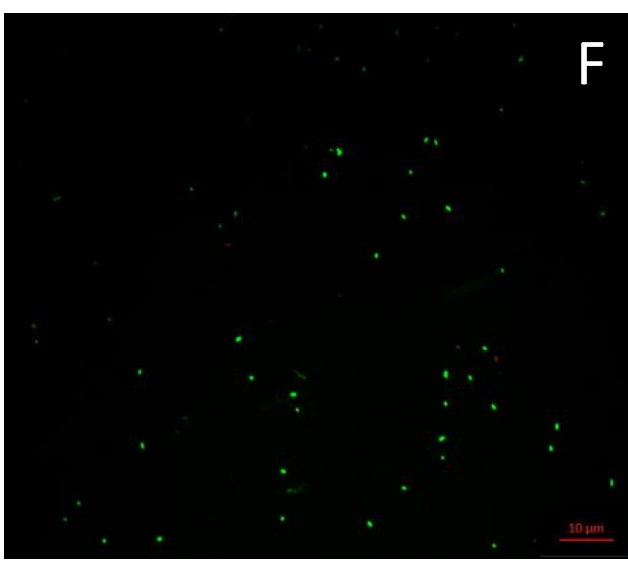

REF-PEG

Figure 8. Live/dead assays after $6 \mathrm{~h}$ of incubation. Fluorescence images of the bacteria strains that are present on the supernatant ( $A, B$ and $C=E$. coli and $D, E$ and $F=S$. aureus) from chito3PEG150 hydrogels ( $A$ and $D$ ), from chito3PEG300 hydrogel ( $B$ and $E$ ) and from REF-PEG hydrogel ( $C$ and $F$ ). All the scale bars $=10 \mu \mathrm{m}$.

Live/dead assays performed with the supernatant from the PEG-derived hydrogels containing chitosan (chito3PEG150 and chito3PEG300) and REF-PEG after $6 \mathrm{~h}$ of incubation highlight some interesting phenomena (Figure 8). REF-PEG did not show any red fluorescence in supernatant whatever the strains used, confirming the anti-adhesion properties of PEG. Chito3PEG150 supernatant show partially red fluorescing $E$. coli, thus demonstrating the biocidal effect of chitosan against these strains. The increase of PEG proportion in the hydrogel sample (chito3PEG300) apparently inhibited the chitosan biocidal effect as only green fluorescence bacteria were observed in the supernatant. Moreover, biocidal properties of chitosan were not observed in the supernatant of hydrogels incubated with $S$. aureus.

Altogether, these data underline major points: PEG samples do not particularly show any anti-adhesion properties as the number of adhered $\mathrm{E}$. coli increases by a factor of 9 from $2 \mathrm{~h}$ to $6 \mathrm{~h}$ of adhesion. Moreover live/dead assays have depicted only green fluorescence cells into the supernatant which demonstrates that PEG surfaces has no biocidal properties against E. coli and S. aureus but only anti-adhesion properties ${ }^{56}$. On the contrary, results with chitosan-containing gels are in agreement with previously published data as no adhered bacteria are observed at the surface of both gels after $2 \mathrm{~h}$ or $6 \mathrm{~h}$ of adhesion, whatever the bacterial strains. The combination of chitosan derivative with PEG chains increases the resistance to bacterial adhesion, however, red fluorescence in the supernatant, only observed with $E$. coli, demonstrate the bactericidal effect of chitosan against $E$. coli, in agreement with the literature 6,58 , and according to Devlieghere et al. ${ }^{59}$ and Chung et al.60 who reported that chitosan showed stronger antimicrobial effects for Gram-negative bacteria than Grampositive counterparts.

The commonly-accepted biocidal mechanism of chitosan derivatives have been proposed by Jafari61 in a recent review. According to XPS spectra, positively charged $-\mathrm{NH}_{3}{ }^{+}$groups of chitosan, are observed at the surface of the gels. For example, a XPS spectrum of the N1s core levels is displayed in Figure S4 
and demonstrates the presence of $\mathrm{NH}_{3}{ }^{+}$functions at the surface of the chitosan-based hydrogels at $401.1 \mathrm{eV}^{62}$. The second signal at $398.9 \mathrm{eV}$ is typically attributed to the $-\mathrm{NH}$ bonds ${ }^{63}$. These $\mathrm{NH}_{3}{ }^{+}$groups can bind tightly to the cell wall components or interfere with the negatively charged residues on the bacterial surface, resulting in pore formation in the cell walls thus altering cell permeability ${ }^{61,64-67}$ causing severe leakage of cell constituents, membrane lysis and the death of the cell. However, according to our antibacterial results, bactericidal effect is more pronounced on $E$. coli strains than on $S$. aureus ones. This can be explained by the thickness of the peptidoglycan layer between bacteria ${ }^{68,69}$. Indeed, E. coli, Gram negative, is protected by an outer membrane of liposaccharides, surrounding by a relatively thin layer of peptidoglycans $(7-8 \mathrm{~nm})$. On the contrary, Gram positive bacteria (S. aureus) have no outer membrane but possess a thicker $(20-80 \mathrm{~nm})$ and a more protective peptidoglycans membrane what can difficult the cellular lysis 70, 71. These properties are therefore expected to strongly depend on the chitosan repartition within the PEG network that determines its accessibility to the bacteria. As soft materials, hydrogels are known to easily undergo structural evolutions, especially as a function of water content or temperature. To address this point, the here-prepared hydrogels were stored in the fridge for 6 months $\left(\right.$ at $\left.+2^{\circ} \mathrm{C}\right)$ and then put in contact with $E$. coli and $S$. aureus for $6 \mathrm{~h}$. Bacteria that had adhered to the surface were recovered by scratching and their number determined by CFU counting. The bacteria population in the supernatant was also determined and compared to a control suspension kept for $6 \mathrm{~h}$ in the absence of hydrogel.

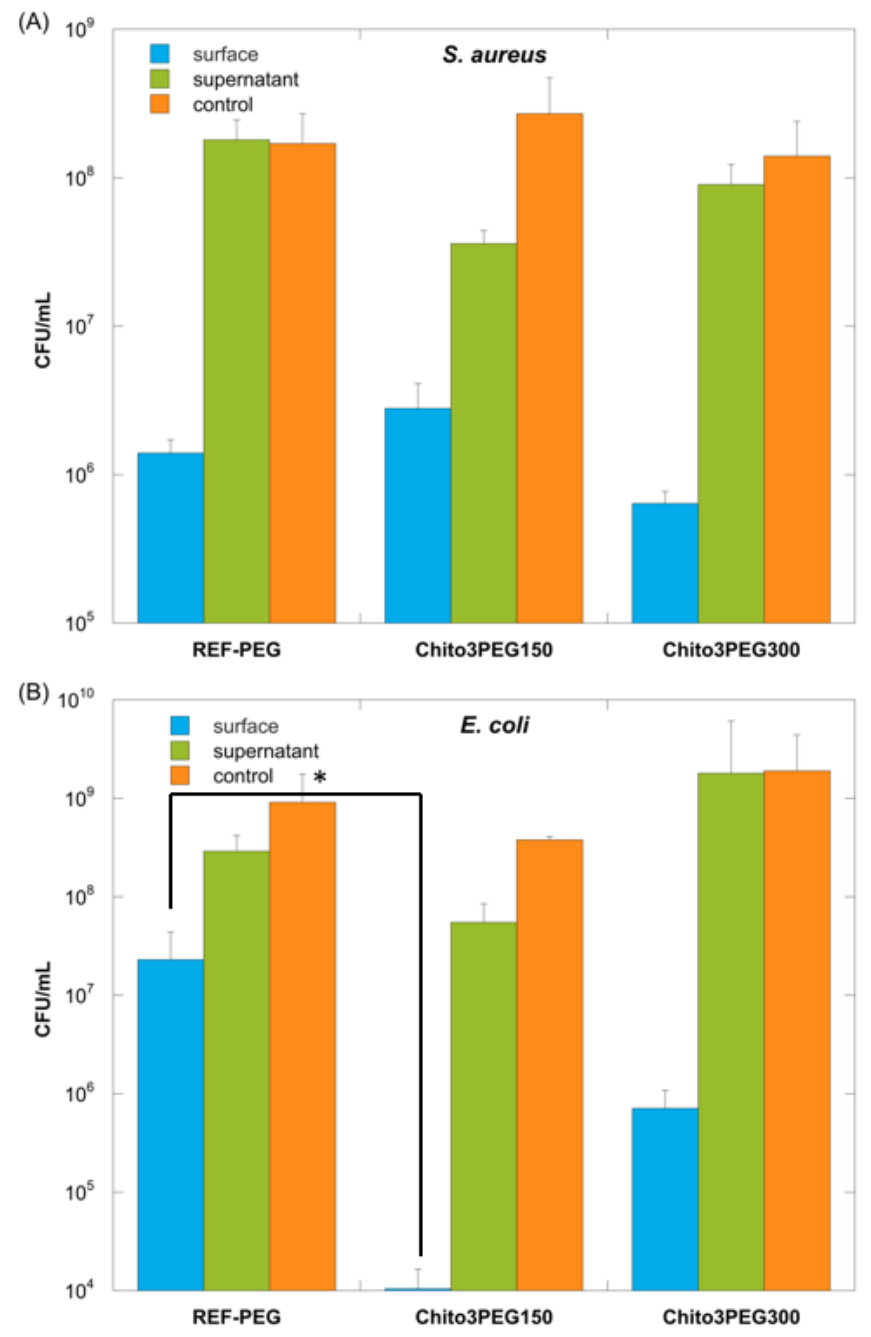

Figure 9. Comparison of the anti-bacterial adhesion properties of REF-PEG, chito3PEG300 and chito3PEG150 hydrogels after 6 months ageing against (A) S. aureus and (B) E. coli as determined by living bacteria population (CFU/mL) on the hydrogel surface (blue), in the hydrogel supernatant (green) and in a control suspension (orange) after $6 \mathrm{~h}$ of incubation. (* is statistically different with $p<0.05$ from ANOVA with Tukey post-hoc test).

As shown on Figure 9, compared to the REF-PEG hydrogel, no significant variation (i.e. less than 1 log difference) in adhered bacterial population was observed for the chitosanbearing gels in the presence of $S$. aureus. In contrast, a decrease of ca. 3 logs was measured for chito3PEG150 compared to REFPEG in the presence of $E$. coli whereas chito3PEG300 showed comparable result to the PEG hydrogel. Altogether, when data after $6 \mathrm{~h}$ incubation are compared for as-prepared and 6-month stored coatings, chito3PEG150 containing gels preserved high antibacterial properties against $E$. coli but not $S$. aureus while chito3PEG300 has lost any significant efficiency compared to the REF-PEG materials for both strains. Noticeably, the supernatant and control CFUs did not differ significantly in any of the conditions. This suggests that no bactericidal molecules, and in particular no chitosan, were released in significant amount 
during the experiment, strongly suggesting that the chemical integrity of the hydrogels was preserved during storage. It can therefore be assumed that some reorganization of the hydrogel structure, including the accessibility of the chitosan chain on the surface, has occurred during ageing.

\section{Discussion}

Photopolymerizable chito-MA were obtained via an EDC/NHS coupling. The initial chitosan has an acetylation degree of $20 \%$ and the degree of substitution is $27 \%$, meaning that ca. $20 \%$ of the amine groups bear a cross-linkable unit. The molecular weight of starting chitosan being 90,800 g.mol-1, i.e. ca. 530 saccharidic units, there is 106 methacrylamide groups per chain, distant by 5 units (ca. 3620 g.mol ${ }^{-1}$ ). Stated differently, $1 \mathrm{~g}$ of chito-MA contains $97.10^{-3}$ moles of methacrylamide moities. As a comparison, PEG-DA chains (596 g.mol-1) bear two polymerizable acrylate end groups so that $1 \mathrm{~g}$ of this polymer contains $3.10^{-3}$ moles of acrylate functions. Starting from PEGDA alone, kinetics data show that the gel formation is fast, with a relatively high conversion rate ( $>90 \%$ ). TGA and DMA analysis indicate a rather homogeneous structure and high modulus (ca. $30 \mathrm{MPa}$ ). Swelling studies indicate a low swelling ratio and small $M_{c}$ value, suggesting a high density of cross-linking. Noticeably, the $M_{c}$ value, ca. $200 \mathrm{~g} \cdot \mathrm{mol}^{-1}$, is significantly smaller than the length of the PEG chain. Such a variation has already been observed by Cruise et al. ${ }^{24}$ that obtained $M_{c}$ values ranging from 150 to 1950 g.mol ${ }^{-1}$ for hydrogels synthesized with PEG molecular weights of 2000 and 20,000 g.mol ${ }^{-1}$ respectively. This suggests that besides reactions between acrylate end groups, addition reactions can occur with radical species formed on the PEG backbone. Indeed, PEG-diacrylate is an $\mathrm{H}$-donor monomer and upon light irradiation, a PEG-sensitized reaction may occur via an $\mathrm{H}$-abstraction mechanism ${ }^{56}$, involving PEG backbone and radicals which are formed from the photolysis of the photoinitiator.

Keeping PEG-DA content constant, addition of chitoMA slows down the photoinduced gelation reaction but improve the final conversion rate up to $100 \%$. In these chito3PEG300 materials, the 1:93 weight ratio corresponds to a low 1: 22500 polymer molar ratio. However, in terms of polymerizable groups, it corresponds to a 1:4 methylacrylamide: acrylate ratio, making the cross-linking reaction between the two polymers highly probable and explaining why, despite the low chitosan:PEG molar ratio, the introduction of chito-MA has such a significant influence on the hydrogel property. Thus the increase conversion rate should sign for the formation of these new chito-PEG bridge formation while the decrease in gelation rate may be attributed to the higher viscosity of the starting solution, as evidenced by the $\mathrm{G}^{\prime}$ values before illumination shown on Figure 2 .

The resulting hydrogels are opaque, indicating the formation of domains of dimensions larger than ca. $400 \mathrm{~nm}$. TGA shows that the main degradation event of REF-PEG at 410 ${ }^{\circ} \mathrm{C}$ is preserved while a new peak that can be attributed to chitosan in found near $350{ }^{\circ} \mathrm{C}$. However, a weak thermal event found at $550^{\circ} \mathrm{C}$ for REF-PEG is now more intense and shifted to ca. $495{ }^{\circ} \mathrm{C}$ in chito3PEG300. It is therefore possible to suggest that it corresponds to the end part of the chitosan chain that are involved in the formation of cross-links and may differ in stability between PEG-PEG and PEG-chito bridges. In this context, DMA analysis show a strong decrease in $\mathrm{Tg}$ between REF-PEG and chito3PEG300 as well in the storage modulus. Such a variation is usually attributed to an important decrease in cross-linking density, which is supported by the more than 10fold increase in $M_{c}$. Noticeable, this $M_{c}$ value for chito3PEG300 (ca. 3400 g.mol${ }^{-1}$ ) is very close to the above estimated molecular weight of saccharide units separating two methylacrylamide groups on the chitosan backbone. This points out again the key role of the chitosan chains in the properties of the hydrogels. Finally, we have pointed out that DMA experiments indicate the presence of several domains of close $\mathrm{Tg}$, and therefore of close structures, in these samples, which should reflect various degrees of cross-linking within the hydrogels. Taken together these data suggest that the photoinduced formation of chitosan-PEG links occurs at the detriment of PEG-PEG bridge and induce an overall thermal and mechanical destabilization of the hydrogel structure.

Properties of the chito3PEG150 hydrogel provide additional insights about the underlying mechanisms. In terms of kinetics, decreasing the PEG content slows down the gelation reaction but the final conversion remains $100 \%$. As the initial viscosity of the solutions with 150 and 300 mg PEG-DA are not significantly different, it can be suggested that this slowing down results from a dilution effect. From the TGA analysis, broadening of the peaks renders a precise determination of the maxima difficult but the overall thermogram is very similar to the one of chito3PEG300, with an apparent decrease in the temperature of the central peak that was attributed to the PEG network. Again, this can be related to the lower initial PEG content. However DMA analysis show a very sharp decrease in modulus (by a factor of ca. 5) but also suggests the existence of at least three very different domains with $\mathrm{Tg}$ (i) close to chito3PEG300, (ii) close to REF-PEG and (iii) at much higher temperature than REF-PEG. Based on the literature, it could be suggested that the last domain corresponds to a phase where PEG concentration and/or cross-linking density is higher than in REF-PEG 57. However, this would be difficult to understand considering that PEG concentration is lower than in chito3PEG300, defavoring PEG-PEG interactions. Noticeably, measured $M_{c}$ value for this hydrogel is larger than for chito3PEG300 which indicates that, on average, the crosslinking density is lower. This would not easily fit with the coexistence of REF-PEG and chito3PEG300 domains, that both have smaller $M_{c}$ values than chito3PEG150, and a PEG-rich domain that would also have a small $M_{c}$ parameter. Therefore, the most plausible explanation is that this domain with high $\mathrm{Tg}$ contains both PEG and chitosan but with higher concentrations and/or cross-linking density than in chito3PEG300. 
Noticeably, our study of the antibacterial activity of the different hydrogels provide additional information on their structure. Fresh substrates allow to observe the well-known anti-adhesion effect of PEG chains. The bactericidal efficiency of chitosan was also confirmed for both chito3PEG300 and chito3PEG150 and for both bacterial strains at the surface of the hydrogels, suggesting that some polysaccharide chains are available for direct contact interactions. Since the $M_{c}$ values for these gels are relatively high and comparable to the length between two cross-linking points, it is possible to assume that chitosan fragments are flexible enough to protrude out of the surface into the culture medium. This would allow them to interact with surrounding bacteria without requiring their adhesion on the surface of the gel, that is significantly prevented by the PEG chains. While such a configuration of the chitosan chains should restrict their mobility compared to free polymers, and therefore their ability to interact with the bacterial cell wall through $-\mathrm{NH}_{3}{ }^{+}$groups of chitosan derivatives, it is possible to assume that their mode of action remains similar to other chitosan forms

However, when looking in the supernatant, only one type of substrate, chito3PEG150, and one type of bacteria, $E$. coli allowed to evidence dead bacteria. While the bacteria strain-dependent effect was in agreement with the literature, the difference between the two hydrogels was more unexpected. Furthermore, after ageing the hydrogels for 6 months, it was observed that chito3PEG150 has preserved its ability to prevent bacterial surface colonization and only for E.coli. This suggests that chitosan chains are more available on the surface of chito3PEG150 than on chito3PEG300 but also that they are less impacted by the ageing process. Coming back to the DMA data, it is possible to suggest that these chains are incorporated in the domain with the highest thermal stability $\left(\tan (\delta)\right.$ peak at $\left.+2{ }^{\circ} \mathrm{C}\right)$. This in turn would confirm our previous hypothesis that such domains do not contain only PEG chains but a mixture of PEG and chitosan monomers.

\section{Conclusions}

Chitosan-PEG hydrogels with antibacterial properties can be prepared under UV-light irradiation in less than 2 minutes. The introduction of methylacrylamide chitosan allows for full conversion of the methacrylated functions of the PEG derivatives but these new hybrid bridges occur at the expense of the PEG network cross-linking, decreasing the hydrogel thermal and mechanical stability. Decreasing PEG content further destabilizes the hybrid network and leads to the formation of different structural domains in the materials. However, this process reveals beneficial to the antibacterial activity of the hydrogel. The resulting chitosan-PEG hydrogels demonstrated a tremendous inhibition (100\% of inhibition) of the adhesion of Escherichia coli and Staphylococcus aureus after many ours of incubation. After 6 months ageing, one of the hydrogel preserved a high antifouling activity against Escherichia coli. Considering that many other polysaccharides or proteins can be easily functionalized with photopolymerizable groups, this strategy can be applied to a wide range of other biofunctional systems.

\section{Conflicts of interest}

"There are no conflicts to declare".

\section{Acknowledgements}

Dr. Davy-Louis Versace would like to thank the French National Research Agency (ANR), UPEC and CNRS for financial help.

\section{Notes and references}

1. R. S. Evans, R. H. Abouzelof, C. W. Taylor, V. Anderson, S. Sumner, S. Soutter, R. Kleckner and J. F. Lloyd, AMIA Annual Symposium proceedings. AMIA Symposium, 2009, 2009, 178-182.

2. CDC, MMWR Morb. Mortal. Wkly. Rep. , 1992, 41, 783-787.

3. R. M. Klevens, J. R. Edwards, C. L. Richards, Jr., T. C. Horan, R. P. Gaynes, D. A. Pollock and D. M. Cardo, Public health reports (Washington, D.C. : 1974), 2007, 122, 160-166.

4. S. S. Magill, J. R. Edwards, W. Bamberg, Z. G. Beldavs, G. Dumyati, M. A. Kainer, R. Lynfield, M. Maloney, L. McAllister-Hollod, J. Nadle, S. M. Ray, D. L. Thompson, L. E. Wilson and S. K. Fridkin, New Engl. J. Med., 2014, 370, 1198-1208.

5. P. W. Stone, M. Pogorzelska-Maziarz, C. T. Herzig, W. L. M.;, E. Y. Furuya, A. Dick and E. Larson, Am. J. Infect. Control., 2014, 42, 94-99.

6. E. I. Rabea, M. E. T. Badawy, C. V. Stevens, G. Smagghe and W. Steurbaut, Biomacromolecules, 2003, 4, 1457-1465.

7. R. A. A. Muzzarelli, P. Ilari and M. Tomasetti, Carbohydr. Polym. , 1993, 20, 99-105.

8. R. A. A. Muzzarelli, P. Ilari and M. Petrarulo, Int. J. Biol. Macromol., 1994, 16, 177-180.

9. A. Heras, N. M. Rodríguez, V. M. Ramos and E. Agulló, Carbohydr. Polym., 2001, 44, 1-8.

10. W. Ding, Q. Lian, R. J. Samuels and M. B. Polk, Polymer, 2003, 44, 547-556.

11. K. Kurita, H. Ikeda, Y. Yoshida, M. Shimojoh and M. Harata, Biomacromolecules, 2002, 3, 1-4.

12. M. Rinaudo, Progr. Polym. Sci., 2006, 31, 603-632.

13. V. M. Ramos, N. M. Rodríguez, M. F. Díaz, M. S. Rodríguez, A. Heras and E. Agulló, Carbohydr. Polym., 2003, 52, 39-46.

14. J.-P. Fouassier and J. Lalevée, Photoinitiators for Polymer Synthesis: Scope, Reactivity, and Efficiency, First edn., 2013.

15. Z. Qi, J. Xu, Z. Wang, J. Nie and G. Ma, Int. J. Biol. Macromol., 2013, 53, 144-149.

16. T. Matsuda and T. Magoshi, Biomacromolecules, 2002, 3, 942-950.

17. B. G. Amsden, A. Sukarto, D. K. Knight and S. N. Shapka, Biomacromolecules, 2007, 8, 3758-3766.

18. I. M. El-Sherbiny and H. D. C. Smyth, Carbohydr. Polym., 2010, 81, 652-659. 
19.

O. Yilmaz and E. Yilmaz, J. Macromol. Sci., Part A 2012, 49, 591-598.

20.

T.-M. Don and H.-R. Chen, Carbohydr. Polym., 2005, 61 334-347.

21.

M. Hahn, J. S. Miller and J. L. West, Adv Mater. , 2006, 18, 2679-2685.

22

P. Patel and C. K. Smith, J. Biomed. Mater. Res. A, 2005, 73A, 313-319.

23. K. Arcaute, B. K. Mann and R. B. Wicker, Ann. Biomed. Eng., 2006, 34, 1429-1441.

24. G. Cruise, D. S. Scharp and J. A. Hubbell, Biomaterials 1998, 19, 1287-1294.

25.

S. Halstenberg, A. Panitch, S. Rizzi, H. Hall and J. Hubbell, Biomacromolecules, 2002, 3, 710-723.

26. N. A. Peppas, K. B. Keys, M. Torres-Lugo and A. M. Lowman, J. Control. Release, 1999, 62, 81-87.

27. C. Zhong, J. Wu, C. A. Reinhart-King and C. C. Chu, Acto Biomaterialia, 2010, 6, 3908-3918.

$28 . \quad$ Z. Amoozgar, T. Rickett, J. Park, C. Tuchek, R. Shi and Y. Yeo, Acta Biomaterialia, 2012, 8, 1849-1858.

29. G. Ma, D. Yang, Q. Li, K. Wang, B. Chen, J. F. Kennedy and J. Nie, Carbohydr. Polym., 2010, 79, 620-627.

30. Y. Zhou, G. Ma, S. Shi, D. Yang and J. Nie, Int. J. Biol. Macromol., 2011, 48, 408-413.

31. C. Ulutürk and N. Alemdar, Carbohydr. Polym., 2018, 193, 307-315.

32. P. Deng, C. Zhou, Y. Hou, R. Chen, F. Liang and L. Liao, J. Biomater. Sci., Polym. Ed., 2017, 28, 1324-1337.

33.

C. Schatz, C. Viton, T. Delair, C. Pichot and A. Domard, Biomacromolecules, 2003, 4, 641-648.

34. P. J. Flory and J. Rehner Jr., J. Chem. Phys., 1943, 11, $521-$ 526.

35. T. R. R. Singh, P. A. McCarron, A. D. Woolfson and R. F. Donnelly, Eur. Polym. J., 2009, 45, 1239-1249.

36.

M. M. Meier, L. A. Kanis, J. C. de Lima, A. T. N. Pires and V. Soldi, Polym. Adv. Technol., 2004, 15, 593-600.

37. K. McAvoy, D. Jones and R. R. S. Thakur, Pharmaceutical Research, 2018, 35, 36.

38. M. Condat, C. Helary, T. Coradin, P. Dubot, J. Babinot, M Faustini, S. A. Andaloussi, E. Renard, V. Langlois and D.-L. Versace, J. Mater. Chem. B, 2016, 4, 2842-2850.

39. R. Poupart, A. Haider, J. Babinot, I. K. Kang, J. P. Malval, J. Lalevée, S. A. Andalloussi, V. Langlois and D. L. Versace, ACS Biomater. Sci. Eng., 2015, 1, 525-538.

40. P. Sautrot-Ba, J.-P. Malval, M. Weiss-Maurin, J. Paul, A. Blacha-Grzechnik, S. Tomane, P.-E. Mazeran, J. Lalevée, V. Langlois and D.-L. Versace, ACS Sustain. Chem. Eng., 2018, 6, 104-109

41. N. Teramoto and M. Shibata, Carbohydr. Polym., 2006, 63, 476-481.

42. T. Elschner, H. Wondraczek and T. Heinze, Carbohydr. Polym., 2013, 93, 216-223.

43.

T. Liebert, M. A. Hussain and T. Heinze, Macromol. Symp., 2005, 223, 79-92.

44. T. Liebert, M. A. Hussain, M. N. Tahir and T. Heinze, Polym. Bull., 2006, 57, 857-863.

45. T. Heinze, T. F. Liebert, K. S. Pfeiffer and M. A. Hussain, Cellulose, 2003, 10, 283-296.

46.

M. A. Hussain, T. Liebert and T. Heinze, Macromol. Rapid Comm., 2004, 25, 916-920.

47. M. A. Hussain and T. Heinze, Polym. Bull., 2008, 60, 775783.
48.

49.

50.

51.

52.

53.

54.

4.

55.

56.

56.

\section{7.}

58.

59.

5

60. Y.-C.Chung C.-C. Su Y.-p. Chen, G. Jia, J.C.G. Wang, H.-I. Wu and J.-G. Lin, Acta Pharmacol. Sin., 2004, 25, 932-936.

61. M. Hosseinnejad, S. M. Jafari, Int. J. Biol. Macromol., 2016, 85, 467-475.

62. H. Schmiers, J. Friebel, P. Streubel, R. Hesse and R. Kopsel, Carbon, 1999, 37, 1965-1978.

63. L. N. Bui, M. Thompson, E. McKeown, A. D. Romaschin and P. G. Kalman, Analyst, 1993, 118, 463-474.

64. R. Severino, G. Ferrari, K.D. Vu, F. Donsì, S. Salmieri and M. Lacroix, Food Control., 2015, 50, 215-222.

65. K. Xing, X.G. Chen, M. Kong, C.S. Liu, D.S. Cha and H.J. Park, Carbohydr. Polym., 2009, 76, 17-22.

66. K. Xing, X.G. Chen, C.S. Liu, D.S. Cha and H.J. Park, Int. J. Food Microbiol., 2009, 132, 127-133.

67. Z. Li, F. Yang and R. Yang, Int. J. Biol. Macromol., 2015, 75, 378-387.

68. T. J. Silhavy, D. Kahne and S. Walker, Cold Spring Harb. Perspect. Biol., 2010, 2, a000414.

69. R. G. Bailey, R. D. Turner, N. Mullin, N. Clarke, S. J. Foster and J. K. Hobbs, Biophys. J., 2014, 107, 2538-2545.

70. P. Eaton, J. C. Fernandes, E. Pereira, M. E. Pintado and F. X. Malcata, Ultramicroscopy, 2008, 108, 1128-1134.

71. L-Y. Zheng and J.-F. Zhu, Carbohydr. Polym., 2003, 54, 527630. 